\section{Choroid Plexus Papilloma of the Third Ventricle in an Infant}

To the Editor: Choroid plexus papillomas (CPP) are uncommon intracranial tumors accounting for $0.6 \%$ of all intracranial neoplasms in adults and $3 \%$ of those in children. ${ }^{1-5}$ CPP are benign neuroectodermal tumors of the central nervous system that show a predilection for the lateral ventricle in children and the fourth ventricle in adults. $^{3-8}$ The third ventricle is a rare location for CPP at any age..$^{4,7,8}$ Only very few cases of third ventricular CPP have been reported in infants.

An eight-month-old female was admitted to a peripheral hospital in June 1992 with the history of fever and cough of one week's duration and altered sensorium of one day's duration. Lumbar puncture was performed at the peripheral hospital and the cerebrospinal fluid (CSF) was found to be clear and colorless. Protein and sugar values were normal and there were no cells or bacteria. Her sensorium deteriorated following the lumbar puncture. Therefore, she was intubated and referred to our hospital. On examination at our hospital, she was afebrile and her pulse rate was 129 per minute. She opened her eyes to painful stimuli, flexing all four limbs and breathing spontaneously. There was bilateral papilledema present. Pupils were $1 \mathrm{~mm}$ in size and reactive to light. The deep tendon reflexes were exaggerated and there was bilateral ankle clonus. There was no neck stiffness. The head circumference was $48 \mathrm{~cm}$ and the anterior fontanel was tense and bulging. An urgent computed tomography (CT) scan was obtained and it showed gross dilatation of the lateral ventricles and an intra-third ventricle hyperdense mass with irregular margins that was enhanced well with contrast (Figure 1). Digital subtraction angiography showed the tumor to be very vascular, being supplied by hypertrophied and elongated medial posterior choroidal arteries. The late films showed a persistent tumor blush. A ventriculoperitoneal (VP) shunt was placed as an emergency. Postoperatively the patient's condition improved remarkably. As the parents refused further treatment, she was discharged a week later. She was readmitted in August 1992 with ascites. The shunt was exteriorized. The initial output of CSF was $1400 \mathrm{~mL}$ per day (drainage pressure set at $10 \mathrm{~cm} \mathrm{H}_{2} \mathrm{O}$ ) and she required fluid resuscitation. Subsequently, the output decreased as the drainage pressure was elevated and it varied from 500 $\mathrm{mL}$ to $700 \mathrm{~mL}$ per day. As the parents remained stubborn and refused craniotomy and excision of the tumor, the shunt was revised and she was discharged. Six weeks later the child was brought to us for definitive surgery. Surprisingly, the ascites had totally subsided despite the presence of the VP shunt. A repeat CT scan showed good decompression of the ventricles. A right frontoparietal craniotomy was performed and the tumor was approached through the transcallosal route. The bright pink tumor was visible through the large foramen of Monro. By gentle manipulation, the vascular pedicle was approached, coagulated and divided. The tumor could be removed en bloc. No calcifications or cysts were found in the tumor. Histopathological examination showed the tumor to consist of papillary structures with a vascular connective tissue core. The epithelial cells lining the papillae were cuboidal and uniform. There was no evidence of malignancy. The postoperative period was uneventful. CT scan showed total excision of the tumor. There was bilateral frontoparietal subdural hygroma. It was left alone. The patient was discharged on the seventh day. She was seen in the outpatient clinic nine months later. She was playful, could speak a few words and walked with minimal support. The subdural hygroma had resolved completely.

The incidence of CPP is much more common in infants and children when compared to adults and usually occurs in the lateral ventricles. The third ventricle is an uncommon location. None appeared in the large series of CPP reported by Matson and Crofton $^{3}$ and Raimondi and Gutierrez. ${ }^{6}$ Kendal et al. had one case in their series of 14 benign CPP. ${ }^{9}$ Tomita et al., however, reported a relatively high incidence of third ventricular CPP in their series. ${ }^{7}$ Thus, they found five cases of third ventricular CPP out of a total of 17 CPP. In our series of 76 cases of brain tumors in children under the age of 12 (unpublished data), the single CPP we found was third ventricular in location. The symptoms and signs of CPP of the third ventricle in infants are due to hydrocephalus. ${ }^{7,8}$ Hydrocephalus is caused by obstruction of CSF pathways and/or hypersecretion of CSF. ${ }^{8}$ The initial CSF output in our case, after converting the VP shunt



FIGURE 1. CT scan of head showing gross dilatation of the lateral ventricles and an intra-third ventricle hyperdense mass with irregular margins. 
to an external ventricle drainage, was nearly 1.5 liters. It is curious that the ascites did not recur after the shunt revision. The CT scan findings of CPP are nonspecific. Three-fourths of these are either isodense or hyperdense and the remainder are hypodense or of mixed density. All of them enhance intensely with contrast. The tumor margins are smooth, lobulated or irregular. Calcifications are seen in one-fourth of them. ${ }^{10}$ Third ventricle CPP are fed by the medial posterior choroidal arteries which are often tortuous, elongated and hypertrophic and displaced posteriorly and superiorly. Draining veins drain into the galenic system. ${ }^{7-9}$ Angiographic tumor blush is usually seen as in our case. The first excision of the third ventricular CPP was by Dandy in 1927. ${ }^{11}$ Most choroid plexus papillomas of the third ventricle can be excised through the enlarged foramen of Monro by the transcortical, transventricular or the interhemispheric transcallosal approach. Asymptomatic subdural hygroma is common after resection of large intraventricular masses. They seldom require surgical drainage. ${ }^{7}$

\author{
Unnikrishnan M, MCh(Neuro) \\ Department of Neurosurgery \\ Khoula Hospital \\ P.O. Box 360 \\ Mina Al Fahal \\ Postal Code 116 \\ Muscat, Sultanate of Oman
}

\title{
References
}

1. Cushing $\mathrm{H}$. Papillomas of the choroid plexus. In: Intracranial tumors. Cushing H, ed. Springfield, Ill, USA. Charles C. Thomas 1932;129-31.

2. Russel DS, Rubenstein LJ. Papillomas of the choroid plexus. In: Pathology of tumors of the nervous system, ed 4, Rubenstein LJ, eds. Baltimore, Williams and Wilkins 1977;220-4.

3. Matson D, Crofton FDL. Papilloma of the choroid plexus in childhood. J Neurosurg 1960;17:1002-27.

4. Gradin WC, Taylon C, Fruin AH. Choroid plexus papilloma of the third ventricle: case report and review of the literature. Neurosurg $1983 ; 12: 217-20$.

5. Bohm E, Strang R. Choroid plexus papillomas. J Neurosurg 1961:18:493-500.

6. Raimondi AJ, Gutierrez FA. Diagnosis and surgical treatment of choroid plexus papillomas. Childs Brain 1975;1:81-115.

7. Tomita T, McLone DG, Flannery AM. Choroid plexus papillomas of neonates, infants and children. Pediatr Neurosci 1988; 14:23-30.

8. Johnson. Management of choroid plexus tumors in children. Pediatr Neurosci 1989;15:195-206.

9. Kendal B, Grosswasser ID, Vallentine A. Diagnosis of masses presenting within the ventricles on computed tomography. Neuroradiol 1983;25:11-22.

10. Kimura M, Takayashu M, Suzuki Y, et al. Primary choroid plexus papilloma located in the suprasellar region: case report. Neurosurg 1992;31:563-6.

11. Dandy WE. Benign tumors of the third ventricle of the brain; diagnosis and treatment. Springfield, IL, USA. Charles C. Thomas 1933. 